\title{
The Relationships of Bacteria Within the Family Bacteroidaceae as shown by Numerical Taxonomy
}

\author{
By ELLA M. BARNES \\ Agricultural Research Council, Food Research Institute, \\ Earlham Laboratory, Recreation Road, Norwich \\ AND H. S. GOLDBERG \\ Department of Microbiology, School of Medicine, University of \\ Missouri, Columbia, U.S.A. \\ (Accepted for publication 5 October 1967)
}

SUMMARY

A comparison, by numerical taxonomy methods, was made of 72 named or freshly isolated strains of Gram-negative anaerobes which were considered to belong within the family Bacteroidaceae. In the first analysis 57 strains were compared. Representative strains were then selected and compared with additional named strains in a second analysis. Four phena were identified: (I) strains of Sphaerophorus, Fusobacterium and Bacteroides melaninogenicus, (2) Bacteroides, (3) unnamed poultry isolates, (4) a second group of unnamed poultry isolates. The most useful differential tests were found to be: $(a)$ cell morphology, $(b)$ the terminal $\mathrm{pH}$ value in glucose broth and the production of formic, acetic, propionic or butyric acids, $(c)$ the production of propionic acid from threonine, $(d)$ growth stimulation by bile, $(e)$ the effect of various inhibitors.

\section{INTRODUCTION}

Difficulties in the identification and classification of the anaerobic non-sporing Gram-negative bacteria were first encountered in studies of the intestinal flora of chickens, when a group of organisms was isolated which bore no resemblance to any named strains (Barnes \& Goldberg, 1962; Goldberg, Barnes \& Charles, I964). It was decided to use the methods of numerical taxonomy in an attempt to assign these organisms to a particular genus and at the same time to eliminate some of the confusion which exists within the family Bacteroidaceae. At present it is difficult even to attach particular characteristics to named organisms since several different classifications are in use (Prévot, 1938; Bergey's Manual 1957; Beerens, Castel \& Fievez, I962), and, owing to the difficulties of maintaining these organisms as freeze-dried cultures, there has been little interchange of isolates between workers of different countries.

The tests used in this investigation were based on the more important characters described in Bergey's Manual (7th ed. 1957) together with those tests which were considered important by Beerens, Schaffner, Guillaume \& Castel (1963). It was hoped to obtain further information on the relationships of various named strains to each other, and also to select key tests for identification purposes, by using strains from as many sources as possible in a combination of tests.

Vol. 51, No. 2, was issued 1 May 1968. 


\section{METHODS}

Sources of organisms. The origin of the strains used in the two computer analyses is given in Table $\mathrm{I}$.

Media and cultural conditions. Details of the media used and conditions of culture have already been described by Goldberg et al. (1964) and Barnes, Impey \& Goldberg (1966). The incubation temperature was $37^{\circ}$ unless otherwise stated.

Table I. The origin of the strains used in the two computer analyses

\section{Source}

Computer analysis

From the National Collection of Type Cultures (NCTC)

Bacteroides necrophorus 7155

B. fragilis 9343

B. melaninogenicus 9337

From the American Type Culture Collection (ATCC)

Bacteroides vulgatus 8482, B. ovatus $8483, B$. thetaiotaomicron 8492 , B. distasonis 8503, B. symbiosis 12829, Sphaerophorus varius 8501, S. necrophorus 12290 , Fusobacterium polymorphum 10953

From Dr H. Beerens (Institut Pasteur, Lille)

Fusiformis biacutus 25, Eggerthella clostridiformis 22, 6I, 353, 354, Ristella variabilis 285

Ristella convexa $265, R$. incommunis $308, R$. variabilis $264,266,267$, Sphaerophorus necrophorus, $S$. funduliformis, $S$. freundii

Sphaerophorus necrophorus Fievez N II 7, N I67, N 252, Fusiformis fusiformis 389

From Dr T. Mitsuoka (Animal Physiology Laboratory, The Institute of Physical and Chemical Research, Tokyo, Japan): isolated from chicken caeca

Strains AIII-45, AU 23-33, $\mathrm{CH}_{32-17}, \mathrm{CH}_{32-20}$ CH 36-9, N 5-43, N209-I 2, N2IO-25, N212-47

Strain AU 2 I -27

From Dr S. M. Finegold (Dept. of Medicine, Wadsworth Veterans Hospital, Los Angeles, California)

Bacteroides melaninogenicus в 477, в 536, в 537

From Dr R. J. Gibbons (Forsyth Dental Centre, Boston)

Fusobacterium polymorphum, Fusobacterium JF 5

$$
\underset{2}{1} \text { and } 2
$$

I and 2

I

1 and 2

2

I

Isolated by the authors

From human faeces-strains $9 / 1$ and $12 / 1$

From chicken caeca-strains belonging to Groups I, 2, 3 and 4 of Barnes \& Goldberg (1965)

Group I, strain EBF 59/96P

Group 2, strains EBF 59/9I P, 95 P

Group 3, strains EBF $61 / 31$ B, 66, 67, 68 and 69

Group 3, strain EBF 61/60 B

Group 4, strains EBF 59/78, 85, 92 P, I00, EBF 60/26, EBF 6I/30, 63

Group 4 , strains EBF $58 / 74$, EBF $59 / 72$, EBF $6 \mathrm{I} / 42,56,6 \mathrm{I}$

From duck caeca-strains EBD I/I B, 3 B and $4 \mathrm{~A}$

From turkey carcass--strains EBT 2/6I and 68

For Bacteroides melaninogenicus strains all the media were supplemented with menadione $0.5 \mu \mathrm{g} . / \mathrm{ml}$. and laked blood $5 \%(\mathrm{v} / \mathrm{v})$ which was prepared by repeated freezing and thawing.

Morphology. Examinations for Gram reaction, size, shape and appearance, were carried out using I8-20 hr. cultures in Reinforced Clostridial Medium (RCM) of (Hirsch \& Grinsted, I954). Colonies on RCM agar (Hirsch \& Grinsted, 1954) or blood agar (Beerens et al. 1963) were examined after 2 or 3 days incubation in a $90 \%$ hydrogen and $10 \%$ carbon dioxide atmosphere. 
Lecithinase. Lecithinase production was determined using the method of Fievez (1963). The egg-yolk plates were examined daily up to 5 days.

Table 2. Characters examined

Test
Morphology
Gram reaction
Shape of cells
Arrangement
Length
Diameter
Colonies on RCM agar
Size
Edge
Surface
Colour
Appearance
Colonies on blood agar
Haemolysis
Growth in RCM broth
20 ${ }^{\circ} \mathrm{C}$
$45{ }^{\circ} \mathrm{C}$
Turbidity
Gas production
Glucose fermentation
Terminal pH
Volatile fatty acids produced
Formic, acetic, propionic or butyric
acids
Fermentation of:
Sucrose, cellobiose, galactose, arabinose,
xylose, mannitol, inositol, salicin, and
glycerol
Cysteine milk
Lecithinase production
Gelatin liquefaction
Indole production
Hydrogen sulphide production
Propionic acid from threonine
Growth stimulation by Io\% bile
Growth in the presence of
Brilliant green I/ Ioo,ooo, penicillin
Io $\mu$ g./ml., neomycin $25 \mu \mathrm{g} . / \mathrm{ml} .$,
polymyxin B Io $\mu \mathrm{g} . / \mathrm{ml} .$, and chlor-
tetracycline ro $\mu \mathrm{g} . / \mathrm{ml}$.
Growth stimulation by menadione

Features scored

Negative or variable

Rods, beaded rods or filaments

Single rods, diplobacilli, or chains

Short $(0.2-0.59 \mu)$, medium $(0.6-3 \cdot 0 \mu)$,

long (over $3 \mu$ )

Slender $(0.2-0.9 \mu)$, stout $(\mathrm{I} \cdot 0-2 \cdot 0 \mu)$

Small (2 mm or less), large (over $2 \mathrm{~mm}$ )

Entire or uneven

Raised or convex

White, grey or black

Opaque or translucent

Negative or $\beta$ haemolysis

Negative or positive

Negative or positive

Flocculent or uniform

Copious or negative

pH 5.5 and below or above pH 5.5

Positive when present at $>\mathbf{I} \mu \mathrm{M} / \mathrm{ml}$.

Negative or acid produced

No change, acid, or acid and clot

Negative or positive

Negative or positive

Negative or positive

Negative, weakly positive, strongly positive

Negative or positive

Negative or positive

Negative or positive

Negative or positive

Biochemical tests. For carbohydrate fermentation, $\mathrm{H}_{2} \mathrm{~S}$ production, indole, etc., additions were made to the basal medium of Beerens (I953-54) as described by Goldberg et al. (1964).

Detection of volatile fatty acids. The volatile fatty acids produced from the fermentation of glucose were determined by the method of Guillaume, Beerens \& Osteux (1956) as modified by Charles \& Barrett (1963).

Bile Stimulation. Stimulation of growth was determined by adding $10 \%$ bile to the Basal Glucose Phosphate (BGP) medium of Barnes \& Goldberg (1962).

Effect of inhibitors. Growth in the presence of brilliant green $\mathrm{I} / \mathrm{I} 00,000(\mathrm{v} / \mathrm{v})$, 
penicillin Io $\mu \mathrm{g} . / \mathrm{ml}$, neomycin $25 \mu \mathrm{g} . / \mathrm{ml}$., polymyxin B Io $\mu \mathrm{g} . / \mathrm{ml}$., or chlortetracycline $10 \mu \mathrm{g} . / \mathrm{ml}$. was tested by adding the required concentration of each inhibitor to RCM broth.

Theonine test. The production of propionic acid from threonine was detected following the method of Beerens (personal communication). This test was later modified by Beerens \& Tahon-Castel (1965). The strains were examined using both techniques.

Characters. The organisms were examined for the characters given in Table 2.

Computer analysis. Both the computer analyses were carried out by $\mathrm{Mr}$ J. C. Gower (Rothamstead Experimental Station, Harpenden, Hertfordshire) using the similarity coefficient defined by Gower (1967) and a single linkage sorting programme (Sneath, I957). The coefficient of similarity used allows for the inclusion of quantitative and multivalue qualitative characters as well as dichotomies for which negative matches do not contribute to the similarity coefficient. A detailed discussion of the choice of coding has been given by Thornley (I967).

In both analyses four tests were recorded as dichotomies, these were the production of formic, acetic, propionic or butyric acids, whilst hydrogen sulphide production was scored quantitatively (Table 2). All of the remaining tests were recorded as alternatives where equal weighting was given to the positive or negative answer. In the first analysis 83 and in the second 86 features were analysed.

\section{RESULTS}

Preliminary computer analysis. In the original computer analysis the main aim was to try and relate the chicken isolates to named strains. As they were intestinal in origin it was considered probable that they would relate more closely to Bacteroides than to the fusobacteria. It was also evident that morphologically they bore little resemblance to Fusobacterium species. Hence most of the named strains used for comparative purposes were either Bacteroides (Ristella in some classifications) or strains designated Eggerthella (Beerens et al. 1963). Only two strains of fusobacteria were included.

The 57 strains tested are listed in Table I, whilst the characters analysed are given in Table 2. All the characters were used with the exception of haemolysis, lecithinase production and growth stimulation by menadione (as Bacteroides melaninogenicus strains were omitted from the first analysis). All of the strains were obligate anaerobes and inhibited by $10 \mu \mathrm{g} . / \mathrm{ml}$. chlortetracycline, none fermented glycerol or hydrolysed gelatin. These properties were therefore omitted from the analysis.

The similarity matrix is shown in Fig. I. Five phena were defined which contained 50 of the strains examined.

(I) Eggerthella clostridiformis. The four strains received from Beerens were identical with Bacteroides necrophorus strain NCTC 7I55. Although at the time of analysis these strains were not considered to form spores, it was subsequently shown that all of these five strains produced spores after prolonged incubation on RCM agar (but not on the VL agar of Beerens). They were therefore excluded from further consideration.

(2) Bacteroides. This phenon included the ATCC strains, those of Beerens and Bacteroides fragilis strain NCTC 9343, together with 8 of the chicken isolates from Mitsuoka. Sphaerophorus necrophorus ATCC 12290 also had a high similarity to the Bacteroides strains. 
(3) Sphaerophorus. The strain $S$. varius ATCC 850 I was closely related to three strains obtained from Beerens. One of the chicken isolates 59/96P also grouped with these strains although having a much lower similarity value.

(4) Chicken isolates. Group 4. Fourteen of the strains previously designated group 4 (Barnes \& Goldberg, 1965) had a low similarity value to either Bacteroides or Sphaerophorus. A full description of these organisms was given by Goldberg, Barnes \& Charles (1964) and the computer results justify their caution in not assigning the organisms to a particular genus.

(5) Chicken isolates. Group 3. A further group of 6 chicken isolates had the lowest similarity to all the other groups. They were originally designated group 3 by Barnes $\&$ Goldberg (1965). They have since been shown to be Gram-positive in very young cultures and their position within the family Bacteroidaceae is thus in doubt.

The only two fusobacteria, Fusobacterium polymorphum and F. biacutus, showed little similarity to each other. Fusobacterium biacutus has since been shown to produce spores (Dr H. Beerens, personal communication) and should therefore be eliminated from the family Bacteroidaceae.

\section{Further analysis of representative strains}

The results from the first analysis were sufficiently encouraging that the computer analysis was repeated to include additional named strains. In particular, three further strains of Sphaerophorus necrophorus were included as the strains originally obtained from Dr Beerens were atypical in certain characters. Two further strains of Fusobacterium were also tested but it was difficult to obtain representative strains of these organisms as they tend not to be maintained in stock culture collections. Four strains of Bacteroides melaninogenicus were added, the requirement for menadione being scored as a separate character. Representative chicken isolates were included, together with a few freshly isolated strains from ducks and turkeys.

Two further tests were used which had been considered important in the differentiation of the pathogenic strains of Sphaerophorus (Fievez, 1963). These were lecithinase production and haemolysis.

In all 40 strains were analysed; of these 25 strains had been used in the first analysis. The additional $\mathrm{I} 5$ strains are listed above. The similarity matrix is shown in Fig. 2. It is evident that the additional strains and the extra tests used widened the differences between the main groups of organisms shown in Fig. I. Four phena were now evident:

(I) Containing Sphaerophorus, Fusobacterium and Bacteroides melaninogenicus together with 3 poultry isolates.

(2) Bacteroides, together with the representative chicken isolate of Mitsuoka.

(3) The chicken isolates belonging to Group 4 (Barnes \& Goldberg, I965).

(4) The most representative chicken isolate belonging to Group 3 (Barnes \& Goldberg, 1965) together with freshly isolated turkey and duck strains.

The family relationships are shown in the dendrogram Fig. 3, whilst the characteristics of the organisms are given in Tables 3 and 4 .

In considering these results the discussion will be confined mainly to representative strains obtained from the Type Culture Collections and other workers. The poultry isolates will be discussed in detail elsewhere (Barnes \& Impey, to be published).

Phenon I: Sphaerophorus, Fusobacterium and Bacteroides melaninogenicus. The main characters which were common to Sphaerophorus and Fusobacterium and which 

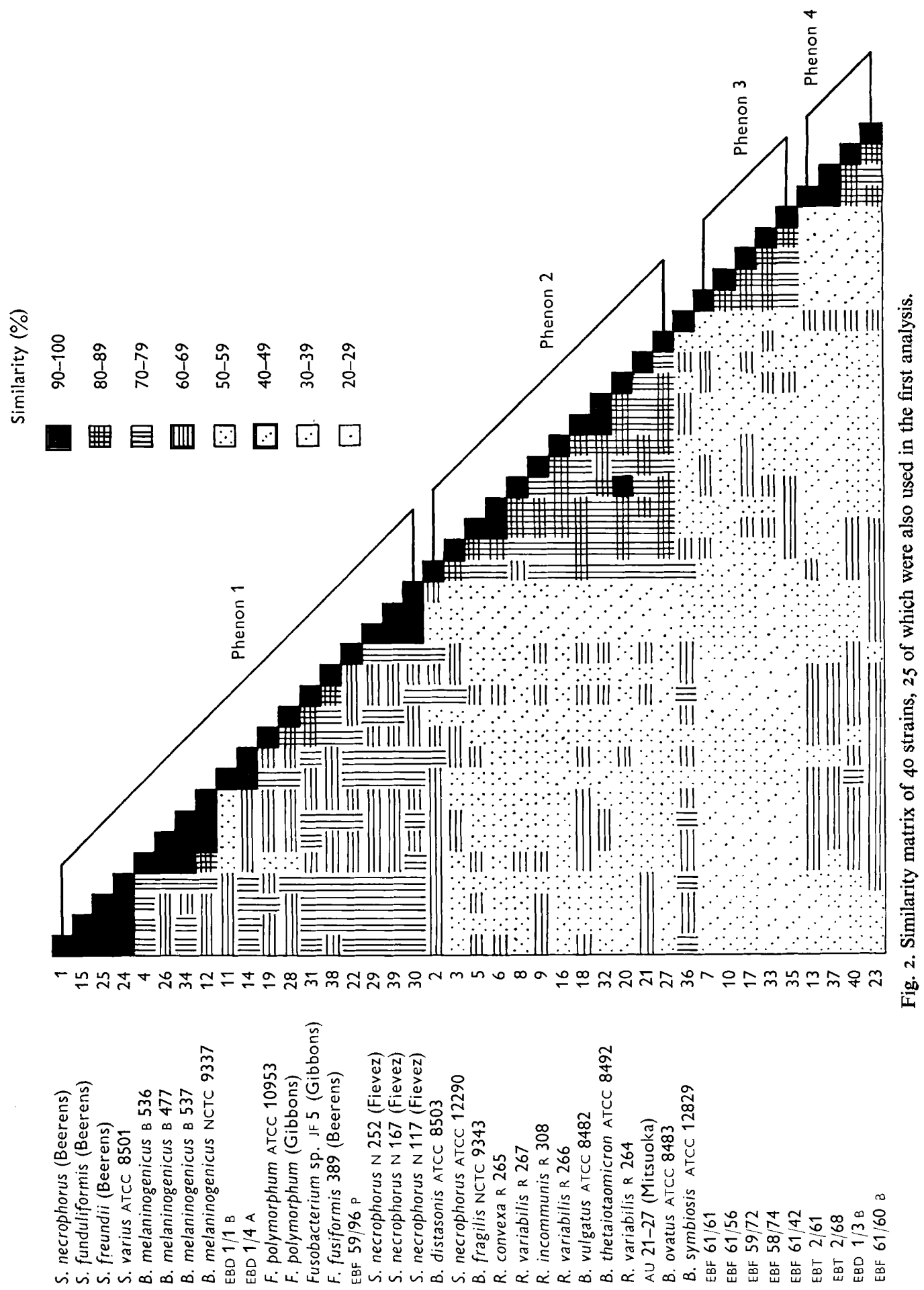
differentiated these organisms from Bacteroides were the production of propionic acid from threonine, the high terminal $\mathrm{pH}$ in glucose broth, the production of butyric acid in glucose broth and the failure to produce acid from most of the other carbohydrates tested. All the strains tested grew in the presence of brilliant green $1 / 100,000$.

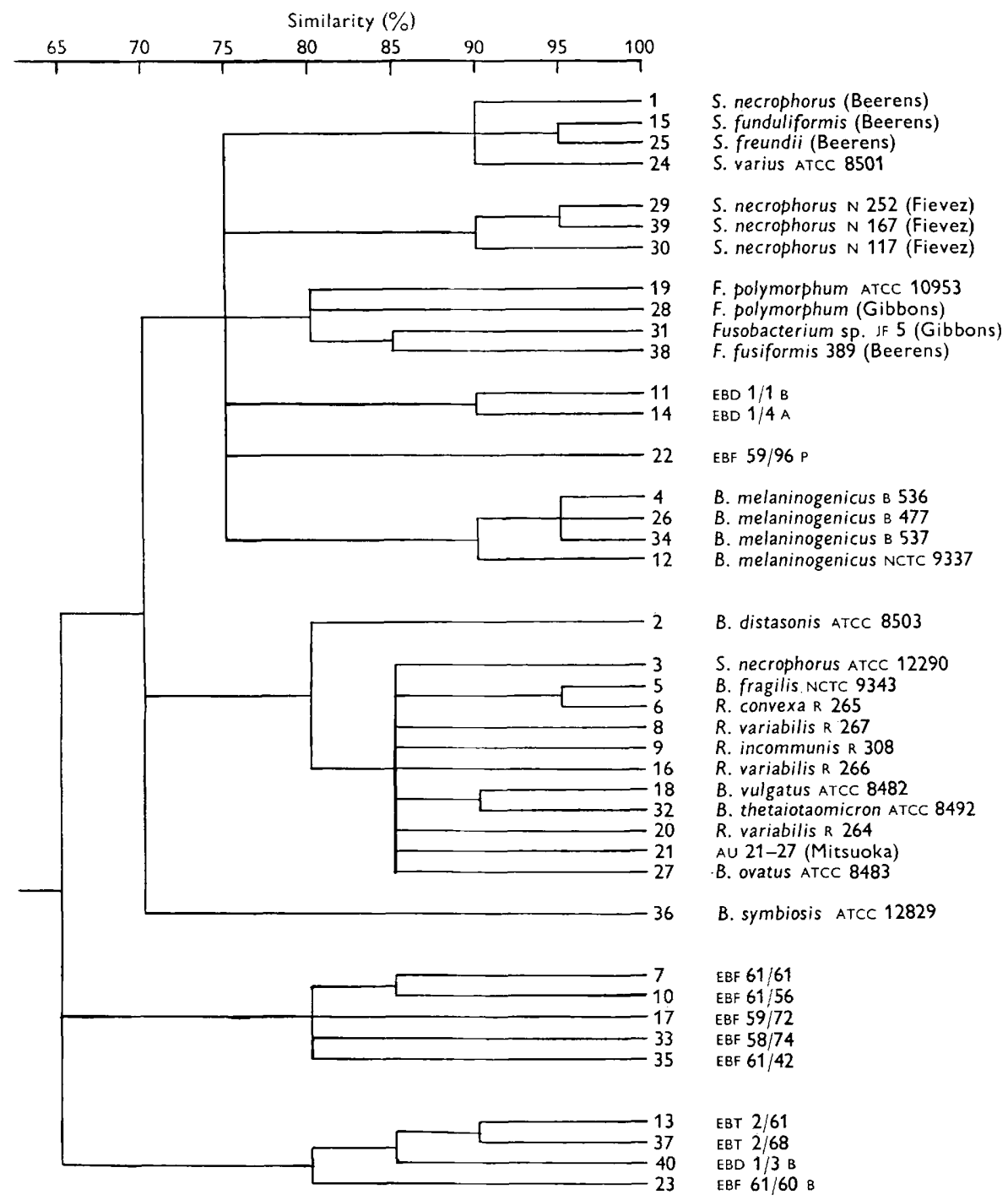

Fig. 3. Taxonomic hierarchy of strains of Sphaerophorus, Fusobacterium, Bacteroides and unnamed poultry isolates.

The strains of Sphaerophorus differed morphologically from those of Fusobacterium. They also produced copious gas, and generally produced propionic acid as well as acetic and butyric acids from glucose. They were inhibited by polymyxin $10 \mu \mathrm{g} . / \mathrm{ml}$. They produced lecithinase and grew at $20^{\circ}$.

The Fusobacterium spp. were characterized by forming long rods or filaments with 


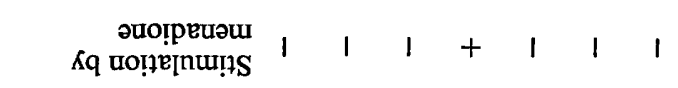

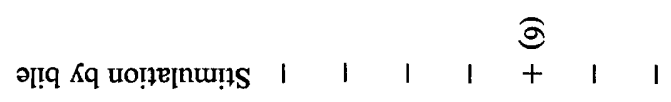
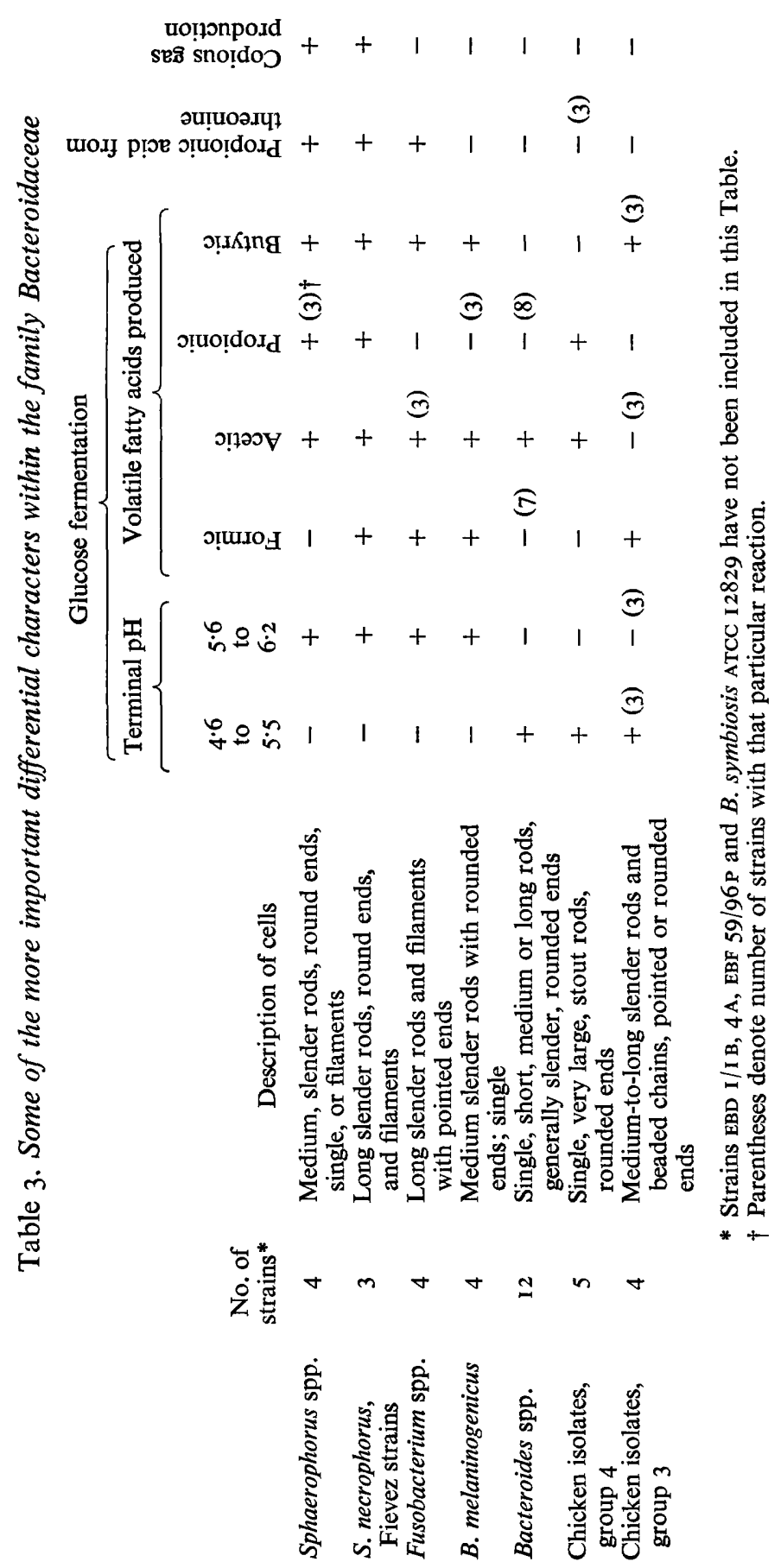


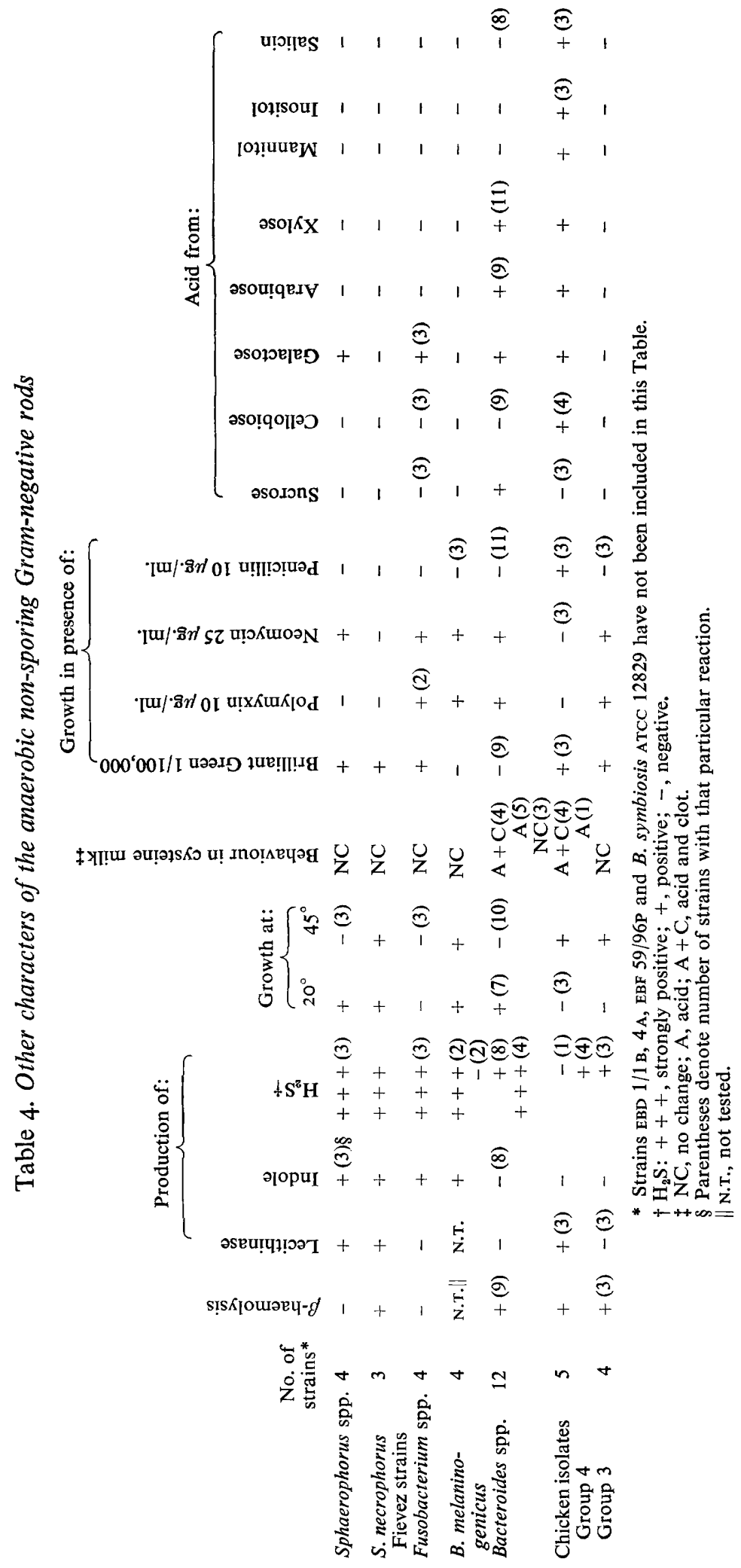


pointed ends; they were non-haemolytic; did not produce lecithinase; did not produce propionic acid from glucose.

The strains of Bacteroides melaninogenicus were related more closely to the Sphaerophorus strains than to Bacteroides. Their resemblance was based partly on their morphology, the production of formic, acetic and butyric acids in glucose broths and their failure to ferment sucrose, cellobiose, arabinose, xylose, mannitol, inositol and salicin. They differed from Sphaerophorus and Fusobacterium in their failure to produce propionic acid from threonine, inhibition by brilliant green $1 / 100,000$, and growth in the presence of polymyxin Io $\mu \mathrm{g}$. $/ \mathrm{ml}$. In these latter three characters they resembled Bacteroides.

Phenon 2: Bacteroides. Morphologically the Bacteroides strains could not be differentiated from Sphaerophorus. The group was differentiated by failure to produce propionic acid from threonine, fermentation of glucose with a low terminal $\mathrm{pH}$ $(4 \cdot 6-5 \cdot 5)$, the failure to produce butyric acid. The organisms grew in the presence of polymyxin $10 \mu \mathrm{g} . / \mathrm{ml}$. and generally fermented a wider range of carbohydrates. Many but not all of the strains were stimulated by bile.

Phenon 3: Chicken isolates (group 4). These organisms were characterised by their large size and shape, the production of acetic and propionic acids in glucose broth and the fermentation of a wide range of carbohydrates, in particular mannitol. They showed a low similarity both to Sphaerophorus and Bacteroides.

Phenon 4: Chicken isolates (group 3). These organisms showed the least similarity to all other groups. In $6 \mathrm{hr}$ broth cultures the organisms had a Gram-positive reaction but tended to be negative in $24 \mathrm{hr}$ cultures. The organisms were very pleomorphic, their shapes ranging from coccoidal forms to long rods. Of the carbohydrates tested only glucose was fermented. Formic acid was produced by all the strains together with trace amounts of acetic and butyric acids with some of the strains.

\section{DISCUSSION}

There have been several detailed studies recently on individual genera within the family Bacteroidaceae, e.g. Fusobacterium (Baird-Parker, 1960), Sphaerophorus (Fievez, 1963), Bacteroides (Beerens et al. I963), and the tests used above were based on those found to be important for each of these genera. The results obtained justify the division of the family into a number of groups but these groups can only be assigned to specific genera after agreement has been reached on the correct nomenclature.

The properties of the Fusobacterium strains agreed closely with those described by Baird-Parker (1960), whilst the Sphaerophorus necrophorus strains (Fievez N I I 7, N I67, $\mathrm{N} 252$ ) conformed with the description of the species given by Fievez (1963), but differed in several characteristics from the other four Sphaerophorus strains tested (Table 4). The close relationship between Fusobacterium and Sphaerophorus which was shown in this analysis is supported by Sebald (I962), who found that the DNA base ratios were similar for the organisms within the two genera and suggested that they should be included together in one genus.

The separation of the Bacteroides strains into a separate group from Fusobacterium and Sphaerophorus is also supported by the DNA base ratio analyses of Sebald (1962) who showed that the $\mathrm{G}+\mathrm{C}$ ratio was $>4 \mathrm{I} \%$ as compared with $27-34 \%$ for the other two genera. Beerens et al. (1963) suggested that many of the species described within the 
genus Bacteroides (or Ristella) should be grouped together within one species Eggerthella convexa. This analysis confirmed the difficulty of differentiating between the various species but certain tests such as those used by Reinhold (1964) to differentiate B. convexus from $B$. thetaiotaomicron were not included.

It is evident that a number of type-culture collection strains have been incorrectly named-in particular the strain Bacteroides necrophorus NCTC 7I 55 which is identical with Eggerthella clostridiformis (Beerens) and does not resemble the other Sphaerophorus strains. The strain S. necrophorus ATCC I2290 is almost certainly a Bacteroides strain. B. symbiosis ATCC 12829 shows little resemblance to the other Bacteroides strains and needs further investigation.

There was no difficulty in recognizing the strains of Bacteroides melaninogenicus because of their typical black colonies and requirements for menadione; however, the taxonomic position of this organism within the family needs careful consideration, It was assigned by Beerens et al. (1962) to a separate genus, and support for this suggestion comes from its low similarity to the other Bacteroides strains.

One of the main purposes of the analysis was to determine which tests were most useful for identification purposes. Perhaps the most difficult problem was initially to determine which organisms might come within the family Bacteroidaceae, which is defined as containing Gram-negative anaerobic non-sporing rods. Strains were included in the first analysis which were subsequently shown to produce spores on particular media. Included amongst these was Fusiformis biacutus which has always been considered a non-sporing organism. Similarly, the Eggerthella clostridiformis strains of Beerens formed spores. The whole relationship of the Gram-negative sporing organisms to the Bacteroidaceae needs further investigation. The problem of obtaining a reliable Gram reaction has again been demonstrated. In these analyses the group 3 chicken isolates were included initially as Gram-negative bacteria but were subsequently found to be Gram-positive. However, they had a low similarity to all the other organisms tested, indicating that they also differed in many other properties.

As can be seen from Table 3, the morphological differentiation of the Sphaerophorus strains from Bacteroides was difficult, but Fusobacterium and the two groups of chicken isolates all had a characteristic morphology. Most of the traditional tests (Table 4) such as indole production, hydrogen sulphide production and the fermentation of various carbohydrates were too variable within the groups to be used to separate them. Amongst the differential tests considered to be most useful are those shown in Table 3. These were: (I) the terminal $\mathrm{pH}$ in glucose broth and the types of volatile fatty acids produced, i.e. formic, acetic, propionic or butyric acids, (2) the production of propionic acid from threonine, (3) growth stimulation by bile. Other useful tests shown in Table 4 included the effect of various inhibitors, in particular polymyxin Io $\mu \mathrm{g} . / \mathrm{ml}$.

The authors are indebted to $\mathrm{Mr}$ J. Gower, Rothamsted Experimental Station, Harpenden, Hertfordshire, for many helpful suggestions and for carrying out the computer analysis. They are also indebted to Mr C. Impey and Mr P. Dickerson for technical assistance. 


\section{REFERENCES}

Baird-PARker, A. C. (1960). The classification of fusobacteria from the human mouth. J. gen. Microbiol. 22, 458 .

BARNes, E. M. \& GoldberG, H.S. (I962). Isolation of anaerobic Gram-negative bacteria from poultry reared with and without antibiotic supplements. J. appl. Bact. 25, 94.

Barnes, E. M. \& GoldberG, H. S. (1965). The bacteroides of poultry caeca and their relationship with human strains. Ernährungsforschung ro, 489.

BARNes, E. M., IMPEY, C.S. \& GoldberG, H. S. (I966). Methods for the characterization of the Bacteroidaceae. In Identification Methods for Microbiologists, Part A, p.51. Ed. by E. M. Gibbs and F. A. Skinner. London and New York: Academic Press.

BEERENS, H. (1953-54). Amelioration des techniques d'étude et d'identification des bactéries anaérobies. Annls Inst. Pasteur, Lille 6, 36.

Beerens, H. \& Tahon-Castel, M. M. (1965). Mise en évidence de l'utilisation de la thréonine par les bactéries anaérobies a gram négatif. Annls Inst. Pasteur, Paris 108, 682.

Beerens, H., Castel, M. M. \& Fievez, L. (1962). Classification des Bacteroidaceae. 8th int. Congr. Microbiol. Montreal, Abstracts, p. 120.

Beerens, H., Schaffner, Y., Gutllaume, J. \& Castel, M. M. (1963). Les bacilles anaérobies non sporulés à Gram négatif favorisés par la bile leur appartenance au genre Eggerthella (nov. gen.). Annls Inst. Pasteur, Lille r4, 5.

Bergey's Manual of Determinative Bacteriology (1957), 7th ed. Ed. by R. S. Breed, E. G. D. Murray and N. R. Smith. Baltimore: The Williams and Wilkins Co.

Charles, A. B. \& Barrett, F. C. (1963). Detection of volatile fatty acids produced by obligate gramnegative anaerobes. J. med. lab. Tech. 20, 266.

FIEVEz, L. (1963). Étude comparée des souches de Sphaerophorus necrophorus isolées chez l'homme et chez l'animal. Bruxelles: Presses Académiques Européennes.

Goldberg, H. S., BARnes, E. M. \& Charles, A. B. (I964). Unusual Bacteroides-like organisms. J. Bact. 87, 737.

Gower, J. C. (I967). A general coefficient of similarity and some of its properties. (Submitted to Biometrics.)

Gutllaume, J., Beerens, H. \& Osteux, R. (I956). La chromatographie sur papier des acides aliphatiques volatile de $\mathrm{C}_{1}$ a $\mathrm{C}_{6}$. Son application a la détermination des bactéries anaérobies. Annls Inst. Pasteur, Lille 8, I3.

Hirsch, A. \& GRINSTED, E. (1954). Methods for the growth and enumeration of anaerobic spore formers from cheese with observations on the effect of nisin. J. Dairy Res. 21, IOI.

Prévot, A. R. (1938). Etudes de systématique bactérienne. III Invalidité de genre Bacteroides (Castellani et Chalmers) dénombrement et reclassification. Annls Inst. Pasteur, Paris 6o, 285.

ReINHOLD, L. (1964). Stoffwechselleistungen bei Stämmen des Genus Bacteroides. Zentbl Bakt. r, I93, 491 .

Sebald, M. (1962). Étude sur les bactéries anaérobies Gram-négatives asporulées. Thèse de Paris. Imprimerie Barnéoud S. A., Laval.

SNEATH, P. H. A. (1957). The application of computers to taxonomy. J. gen. Microbiol. 17, 201.

Thornley, M. J. (1967). A taxonomic study of Acinetobacter and related genera. J. gen. Microbiol. 49, 2 II. 